\title{
The effect of unemployment on the level of wages in the enterprise sector in Poland (2000-2014)
}

\author{
Maciej SZCZEPANIK \\ WSB University in Wroclaw, Poland
}

\begin{abstract}
:
Aim: In the first section of the paper, a brief outline is presented of the economic theory delineating the concept of unemployment and its association with the level of wages. The concept of unemployment and contemporary theories of this phenomenon are discussed. The paper also includes criticism of certain parts of neoclassical theory of the labour market which represents the author's own thoughts. It is concerned especially with the equilibrium price on this market, in other words, the level of wages and labour supply curve. The aim of the paper is to analyze the effect of unemployment on the level of wages in the enterprise sector in Poland.
\end{abstract}

Design / Research methods: Linear correlation between monthly data from 2000 to 2014 were used. Certain measures were employed, such as differencing or shifting time series (in both directions), to avoid the effect of seasonality, that is, of apparent correlation on the study results, and to determine precisely the direction of correlation between variables. This methodology allows for increased reliability of the results produced.

Conclusions / findings: Thanks to that, it was possible to observe a clear statistically significant negative effect of unemployment on the level of wages in Poland in the analyzed period. This effect, on both nominal and real wages, was lagged by one month.

Originality / value of the article: The results of the research represent scientific value added of the paper and can be taken into consideration while making decisions concerned with the country's macroeconomic policy.

Keywords: unemployment, level of remuneration, wages, linear correlation.

JEL: C10

Correspondence address: Maciej SZCZEPANIK, WSB University in Wroclaw, ul. Fabryczna 29-31, 53609 Wrocłąw, Poland. E-mail: Maciej.szczepanik@wsb.wroclaw.pl.

Received: 28.07.2017, Revised: 11.11.2011, Revised: 19.02.2018

doi: http://dx.doi.org/10.29015/cerem.515 


\section{Introduction}

The research concerned with the problem of unemployment and the use of workforce has been conducted throughout the entire period of the development of the economic theory, since the time of classical economics. Attempts have been made at defining the concept of unemployment, seeking to comprehend its nature and forms, causes of its occurrence and the effects of its persistence in the economy. Moreover, guidance and guidelines have been formulated for the economic policy with a view to reducing its incidence. The immense interest devoted to unemployment has largely stemmed not only from the economic but also social and political importance attributed to this phenomenon. The level of unemployment in a particular country or region exerts a considerable impact on the standard of living, the level of economic development, as well as public sentiment, and ultimately the popularity of the government. Long-lasting structural and pathological unemployment is a social phenomenon which is certainly negative (pathogenic and crime-inducing), affecting adversely human mental health. ${ }^{1}$ It is therefore one of the most pressing socio-economic problems that a country in market economies faces (although enterprises may also take part in the reduction of unemployment incidence) (Kwiatkowski 2007: 7-8). The major loss experienced by the society as a result of the unemployment level exceeding natural rate of employment (in the situation of the labour market equilibrium) is obviously the gross domestic product falling below the potential GDP. According to Okun's law, this GDP gap is at 2,5$3 \%$ of $\mathrm{GDP}^{2}$ for every percentage of real unemployment growth above the natural rate of unemployment (depending on the situation of the economy concerned) (Kamerschen et al. 1991: 146-147). Apart from contributing to the fall in domestic production, unemployment reduces state budget revenues (fewer employees pay

\footnotetext{
${ }^{1}$ As evidence, one could cite the so called Clark's curve showing the subjective well-being of the short, medium and long-term unemployed. More on this issue see in, e.g. Oleksyn (1997: 40-41).

${ }^{2}$ One should bear in mind that the GDP gap can differ considerably across economies, diverging from the values given by Okun. In fact, it is difficult to estimate the natural rate of unemployment for a specific economy, and, by inference, the GDP loss caused by an increase in unemployment.
} 
income taxes) and increases government spending (increased expenditure on programs developed to combat unemployment and on social security), which, in a long-term, will lead to higher taxes for the majority of citizens. The burden of longterm unemployment will thus affect the entire society.

One of the critical factors affecting the development of labour supply is unemployment rate. The higher the rate, the larger labour reserves in general which the employer can tap into. A high rate of unemployment lessens the pressure to raise wages and is likely to be a factor in the reduction of real wages.

\section{The concept of „unemployment” in the theory of economics}

Within its contemporary meaning, the term ,unemployment” was introduced at the end of the nineteenth century. The literature nowadays describes an unemployed person as one remaining jobless, seeking and being available to work. These three characteristic features must occur simultaneously for a person to be declared unemployed (Sinclair 1987: 1-3; Godfrey 1986: 6-9). Despite this seemingly straightforward definition, the attributes mentioned raise numerous doubts and stir controversy. Even remaining jobless is not entirely self-understood and unambiguous. An example here could be people who work part-time and who wish but cannot work longer hours. Not classifying them as unemployed will reduce the actual level of unemployment. Likewise, when there are too many employees in an enterprise in relation to the production level the unused workforce potential may be considered to be some sort of hidden unemployment. The problems involved in providing a clear definition also emerge with respect to the two other characteristics of the unemployed. Searching for a job is difficult to define because it can assume diverse forms, while one's availability to work depends on the time frame during which this availability should be demonstrated. What also raises doubts and debates is the condition of the simultaneous occurrence of the three characteristics mentioned before, as it can considerably underestimate the actual level of unemployment. In the literature, this is exemplified by developing countries. In the cities of those countries, it often happens that plenty of people are looking for a job 
but given the poor social security scheme they cannot afford staying without a job, be it even a casual job. On the other hand, across the rural areas of developing countries many people are unemployed, yet only very few of them are searching for a job, since a relatively small number of jobs is offered. Not classifying those people as unemployed underestimates its scale (Sen 1975: 121). Those issues, however, are not closely related to the topic of the paper and therefore will not be elaborated on. ${ }^{3}$

The basic measure of the unemployment level commonly applied globally (despite its shortcomings) is the rate of unemployment, which is the number of persons classified as unemployed divided by the number of economically active persons (labour force resources). The terms „unemployment” and „unemployment rate" used in this paper should be understood as they are defined and measured by the national statistics (GUS [Central Statistical Office] in statistical yearbooks or surveys on economic activity of population - BAEL).

The labour force resources encompass economically active people (working and unemployed) at a specific age. This is of relevance in that people who are not among the working age population and who are economically inactive (not seeking work or unavailable to work) are not classified as labour force at all and their number has no direct impact on the registered unemployment rate. In statistical practice, there are three primary methods applied globally for measuring unemployment. They include the following methods: the number of unemployed as registered by employment offices; the number of registered persons applying for unemployment benefits and surveys carried out on a representative sample of the population. In developed countries (including Poland), the methods that are commonly used are the first and the third of the mentioned. Calculating unemployment based on the number of persons applying for unemployment benefits is rarely employed because of possible measurement errors. The number of people applying for unemployment benefits is largely dependent on the conditions rendering the receipt of benefit eligible, as well as on the amount of benefit. On the one hand, determining the number of the unemployed in this way one may overestimate the scale of the phenomenon, as some persons applying for financial assistance may in fact be not seeking work. On the other hand, the number of the unemployed may be underestimated when a certain

\footnotetext{
${ }^{3}$ For more on this topic, see Kwiatkowski (2007: 13-21).
} 
group of people, actively seeking work, is not applying for the benefits in employment offices because they are not eligible for them. Similar doubts are expressed while calculating unemployment using the number of people registered in employment offices as unemployed. Their number is also dependent on the conditions which have to be met to register and, in addition, on the motivation of the unemployed. If the chances of finding a job through the employment office are small, this will undermine the actual unemployment measured using this method. Moreover, in many countries registering oneself in an employment office is a necessary requirement for being granted benefits, which in turn may overestimate the scale of the phenomenon, since some of those unemployed persons may actually be unavailable and unwilling to work. What one also needs to bear in mind is that for both of these methods at issue the conditions of registration differ substantially across countries and they often tend to change over time, which makes it considerably difficult to compare the scale of unemployment between different countries and even within one country in a long-term. Given the standardization of the definition and the calculation methods recommended by the International Labour Organisation, the most reliable method for making global comparisons (and also those for a given period of time) is the method using a survey to determine the unemployment scale (a wide-spread method in the United States, where it was introduced in the 1940s). In Poland, it was in 1992 that the labour force survey (LFS) was conducted for the first time. The shortcoming of this method is the selection of a random sample which would be representative for the entire country but not for individual regions, where the sample errors may be quite large (Kwiatkowski 2007: 21-26). What also has to be borne in mind is that comparing the scale of unemployment by using different methods may not always prove dependable.

In the literature, one can come across a number of classifications and types of unemployment. The three primary types of unemployment are as follows: frictional, structural and cyclical. This division is important because of the fact that there are different methods for limiting unemployment depending on which phenomenon we are dealing with in a given situation. However, considering the topic of the paper, this issue will not be discussed here. 
An important discovery, from the point of view of this work, are the findings produced by the studies carried out by A.W. Philips, namely a negative relationship found based on statistical analyses between the rate of rises in nominal wages and the rate of unemployment. Discovered in the 1950s during empirical studies, this relationship (the Philips curve), was later on also validated theoretically. Excess of demand over supply on the labour market determines the growth rate of nominal wages. The higher the excess, the faster should nominal wages grow. At the same time, increased work demand should lead to reduced unemployment, if such exists. On the other hand, excessive supply on the labour market brings about a decline in nominal wages, and an increase in excessive supply also leads to an increase in unemployment. This reasoning implies that there is a negative association between the growth rate of minimal wages and the rate of unemployment. Another important finding produced by those studies was that there was a positive level of unemployment even in a situation where there was a balance between supply and demand on the labour market. This finding was later used by American economists M. Friedman and E.S. Phelps, who devised the theory of natural unemployment rate. The concept of the Phillips curve became popular thanks to other economists (P.A. Samuelson and R.M. Solow) who, while determining the functional relationship between the growth rate of nominal wages and the rate of increase of prices, modified the Phillips curve, showing it as a negative relationship between the rate of unemployment and the rate of price increase, that is, inflation. What made this concept so popular was the fact that the conclusions drawn from it could be easily translated into the guidelines drawn up for government policy aimed at reducing inflation or unemployment, owing to their interchangeability. In the 1960s and 1970s the usefulness of the Phillips curve was questioned. It was verified negatively by the economic reality of many developed countries which saw inflation clearly on the rise at that time. The expansion of demand increased the growth rate of prices, yet if failed to reduce the rate of unemployment. This development undermined the theory of interchangeability of these two phenomena. A new modification of the Phillips curve was proposed by M. Friedman and E.S. Phelps, the scholars already cited in the paper. According to their theory, the level of unemployment always tends to approximate natural level of unemployment (unemployment at equilibrium) 
in the long run, with deviations from this state being only temporary. The increase in prices brought about by expanded demand also increases nominal wages, but real wages usually fall in this case. As employees (as well as employers) are above all interested in real and not nominal wages, even if they succumb to money illusion and increase labour supply, thus reducing the unemployment rate (in this situation, employers will willingly hire new workers for a lower real wage), this situation can only be temporary. Realizing that they were wrong about their inflation expectations, workers will adjust to the real inflation demanding the relevant pay rise. This, in turn, will reduce the level of employment to the baseline situation and will increase unemployment. Thus, the government policy will not lead to sustainable reduction of unemployment, but merely to inflation growth. It is, therefore, as Friedman and Phelps believe, ineffective. The relationship between the unemployment rate and inflation is negative only in the short term, which is due to workers' mistaken inflation expectations (money illusion). For the unemployment to be reduced in a sustainable way one should continuously „surprise" the public by accelerating the inflation processes unexpectedly. It is, however, impossible in the long run, for it would lead a country to experiencing a socio-economic crisis. This is why no interchangeability exists in the long run between the level of the unemployment rate and inflation. According to the concept devised by Friedman and Phelps, the long-run Phillips curve is a vertical straight line. The level of unemployment, which can never be entirely eliminated, equals the natural rate of unemployment and is not dependent on the inflation level. This does not, yet, mean that the government has no effective instruments while combating the long-term unemployment linked to natural rate of unemployment. In order to reduce the level of natural rate of unemployment, which in some measure could be identified as frictional and structural unemployment, one has to improve the functioning of the labour market, increase its transparency by facilitating obtaining the information on job offers and on people searching for work, develop training programmes for the unemployed, increase labour mobility, etc. (Kwiatkowski 2007: 140-147).

Today's empirical studies and theory concerned with identifying the relationships between inflation and the rate of unemployment are clear in their assertion that in the long run there is no interchangeability between these two 
phenomena, and so there is no dilemma of having to choose „the lesser evil”. Monetary policy over a long-term is thus neutral, while increased money supply has no lasting impact on the unemployment rate, merely raising inflation. This has been confirmed by the US economy, where the rate of unemployment, from the mid1960 s to the 1990s, was stable (about 6\%) while inflation ranged between 1,6\% and $9,0 \%$, depending on the relevant year. A similar situation was observed in the 1970s in Canada, in majority of Western European countries and in plenty of countries of the Pacific Basin. Analyzing a longer period of time, one can notice that higher inflation does not bring about lower unemployment; nor does lower inflation engender a higher rate of unemployment (Solow et al. 2002: 41-45). This shows that in the long run there is no relationship between the rate of rise of nominal wages and the unemployment rate, as described by Phillips.

In addition to Friedman and Phelps's theory of natural rate of unemployment, in which the Phillips curve is modified, other concepts emerged later on rejecting entirely the findings of Phillips's work. Some researchers, adopting the hypothesis of the population's rational inflation expectations (not succumbing to money illusion), found that the Phillips curve was vertical also in the short term, and therefore no negative relationship existed between the unemployment level and inflation, be it even temporary. This approach negates completely the meaning of the original Phillips curve and the findings stemming from it regarding the policy aimed at reducing unemployment (Kwiatkowski 2007: 146). In their majority, economists reject the original Phillips curve considering it to be a long-term vertical straight line, while some economists recognize the temporary ,interchangeability” between the rate of unemployment and inflation in the short run, depending on the methods, the research scope and its assumptions, with some others rejecting the negative relationship between those measures entirely, even over a short period. ${ }^{4}$

In the 1980s one more theory of equilibrium unemployment was advanced which ought to be mentioned here given its considerable popularity and plenty of

\footnotetext{
${ }^{4}$ The assumption that the population will not succumb to money illusion seems far-fetched and contrary to reality. Moreover, the basic problem encountered when examining the Phillips curve in the short run is the fact that it is not a function relationship. Economic phenomena and processes such as inflation and the unemployment rate are often interdependent, while in the case of a function one variable must be independent.
} 
advocates, also today. A group of British economists, while referring to the theory of natural rate of unemployment, created a new theory of non-accelerating inflation rate of unemployment (NAIRU). Its creators, not unlike their predecessors, see the relationship between inflation and unemployment. A relatively low level of unemployment implies inflation growth, which is due to greater bargaining power enjoyed by trade unions and workers in wage negotiations and the difficulties faced by employers in finding people willing and available to work. This is directly reflected in increased wage pressure and ultimately in the intensification of inflationary processes. In the situation of a sufficiently high unemployment the wage pressure decreases, workers are forced to accept lower wages, which leads to the weakening of inflation dynamics. The conclusion stemming from this kind of reasoning is that there must be a level of unemployment in the economy which stabilizes the dynamics of inflationary processes. This level is called NAIRU. It is of considerable significance for the government macroeconomic policy given that by influencing the level of real unemployment one can slow down or accelerate the inflation rate. The unemployment that rises over the NAIrU level (e.g. by limiting the overall demand) will bring about the lowering of wage pressure, reduction of the inflationary process dynamics, or it can even lead to the fall of the overall level of prices. The crucial element of this theory from the point of view of this paper is the assumption that at a given time every economy has a specific level of real wages which is consistent with its economic capacities. If workers are successful in negotiating wages which are higher than this level, then it will cause an acceleration of the inflation rate; if, on the other hand, wages are lower than the economic capacity of the economy, then it will bring about slowing down the inflationary process dynamics. The inflation stabilization will occur when the wages proposed equal the level of wages determined by the economic realities at the time concerned, and the then present level of unemployment is precisely the NAIRU (nonaccelerating inflation employment). Naturally, the level of wages corresponding to the economic capacities of the economy concerned may change over time, being primary dependent on work productivity. Nor is the level of NAIRU constant over time (just like the level of natural rate of unemployment), yet its determinants will 
not be discussed here since they are not closely related to the topic of the paper (Kwiatkowski 2007: 147-154).

An interesting theory, whose underlying basis was formed by the research conducted in many countries of Europe, Asia and North America, was presented in the mid-1990s by Blanchflower and Oswald. ${ }^{5}$ Analysing the microeconomic data on unemployment and the levels of pay, with those data being produced based on the surveys carried out in numerous countries over a dozen or so years (in the 1970s and the 1980s), they wrote a paper which was very critical of the neoclassical approach towards the labour market. The results produced by their calculations found regularities which would hold whatever the timeframe of the study, country or region analysed. The regularity found between the unemployment rate and the level of local wages the scholars called a wage curve. The findings elicited by the empirical research and calculations left no doubts. In all the countries examined (e.g. USA, the UK, former Federal Republic of Germany, Canada, Austria, Japan, Indie, South Korea, Norway, Sweden, the Switzerland, the Netherlands, Italy, Ireland) a statistically significant relationship was discovered between wages and unemployment. This relationship proved to be negative, while the elasticity of the unemployment rate in relation to wages being at approximately $-0,6^{6}$ across all the countries. The association thus discovered was contrary to the earlier theories on the labour market. Previously (in the 1970s and 1980s) the majority of economists, based on the logical analysis transformed into an economic theory, recognized the positive correlation between unemployment and the level of pay across a region or

\footnotetext{
${ }^{5}$ More on this topic see Blanchflower (1994). The research conducted by the authors was based on microeconomic data describing regional (in geographical terms) labour markets and specific industries. Thus, all the findings stemming from their book also pertain to markets. The data came from the surveys conducted in a similar way across all the countries, while the methodology applied in the calculations was uniform in all the cases so as to be able to compare the results.

${ }^{6}$ A few years later, Blanchflower conducted studies on a wage curve in Central and Eastern European countries, among others in. Albania, Armenia, Belarus, Bulgaria, Croatia, the Czech Republic, Lithuania, Latvia, Estonia, Russia, Poland, Romania, Slovakia, Slovenia, Ukraine. The findings confirmed the existence of a wage curve also in those countries. The elasticity of the unemployment rate in relation to wages in the countries of Central and Eastern Europe ranged between $-0,1$ and $-0,3$, which suggests that it proved bigger than in the countries described in the previous research. See more in Blanchflower (2001).
} 
in a particular industry. This relationship was explained by the fact that only being able to land a well-paid job can keep local unemployment high, because with lower wages people will move somewhere else, and unemployment will fall. Hence the higher the pay in a region or an industry, the higher the unemployment rate and vice versa. The studies by Blanchflower and Oswald, as well as those conducted by other economists ${ }^{7}$ refuted this theory. Analyzing a huge volume of data, they provided evidence that over a specific period high local unemployment (or across an industry) was linked to low earnings, while a low rate of unemployment occurs together with high wages. In a situation where there is high unemployment in a region or industry employers do not have to motivate employees by offering high wages as labour supply exceeds labour demand, even with relatively low wages. In addition, employees do not call for pay rise because they are afraid of losing their job. This is a case in which employees and the unemployed simply do not enjoy a strong bargaining position. Of course, exactly the opposite happens when there is low local unemployment. The research findings show a negatively sloped wage curve. One should emphasise that although the wage curve resembles the Phillips curve, it has a completely different meaning. The Phillips curve is usually estimated based on macroeconomic data (the wage curve on micro data) and is referred to the adjustment process unfolding between inflation and unemployment, which, in its very assumption, implies a lack of labour market equilibrium. In long-run equilibrium, according to most concepts, the Phillips curve becomes a vertical straight line. The proposal put forward by Blanchflower and Oswald alters the neoclassical way of thinking about the labour market. According to their theory, a downward-sloping ,wage curve”, and thus unemployment as well, is present when the labour market is in equilibrium, with the Phillips curve roughly resembling a kind of an aggregate ,wage curve”. Evidence showing a negative correlation of the unemployment rate with the level of pay is hard to reconcile with the classical theory on competitive labour market, where high unemployment suggests a lack of

\footnotetext{
${ }^{7}$ For example Buettner (1999); Holmlund (1991) - strong evidence that there is a negative relationship between the unemployment rate and local pay; higher unemployment reduces the level of real wages.
} 
equilibrium and it is linked to excessively high real wages (Blanchflower, Oswald 1994: 359-368).

From the point of view of the primary aim of this paper, defining the effect which the level of unemployment has on wages in economy is of major interest. In modern theories of economics one can come across numerous links, both direct and indirect, between these two phenomena. In the first place, an increase in the unemployment rate raises competition on the part of labour supply raising fears among workers about losing their jobs. This directly reduces the pressure on pay rise. A falling rate of unemployment will obviously be a factor compelling workers to demand higher wages given the employer's difficulties in finding good employees. What should also be mentioned is that the experiences of developed countries clearly suggest that the reaction of wages towards falling unemployment is considerably stronger than wage sensitivity to an increase in unemployment. This means that an increase in wage pressure in the situation of a reduced rate of unemployment is much higher than its decrease when unemployment grows by the same value. It should be stressed that this kind of reasoning is in line with the labour market theory. With the assumption of elastic nominal wages, unemployment which is above its natural rate implies a tendency for real wages to fall, for in this situation there will always be workers willing to work for lower wages than the market rate. This will prompt employers to increase their labour force. On the real labour market a certain rigidity in nominal wages naturally exists, as well as limitations to the mobility of workers and the lack of information transparency, which all inhibit adjusting labour demand to labour supply (Kwiatkowski 2007: 149-152).

Concluding this section of the paper, criticism will be presented as regards some parts of the theory of classical labour market. According to it, high unemployment tends to be related to excessively high real wages. Through the reduction of this wage rate, which should be effected by the market mechanism, labour demand and supply will become equal (demand will grow and excessive supply will decrease). This may take long time given the existence of market imperfections such as downward rigidity of nominal wages, trade union activity, etc. All those „imperfections" outlined in the economic theory are predominantly on the side of labour supply, that is, workers who are not easily convinced to have their wages 
reduced. Seeing the labour market in this way, one might forget that labour is a very specific good of which supply is not solely dependent on price. For a vast majority of people, work, as the main (and sometimes only) source of income, does not follow the classical economic laws because its some supply (ensuring survival) must be delivered to the market. A single worker who has no influence on the price at which he sells his labour is not sovereign when deciding what amount of labour to sell at the set price, nor, all the more, when deciding whether or not to give up selling this good on the market because the price is too low in relation to the costs of livelihood he has to incur. Expanding the analysis by taking into account this paramount assumption, one may conclude that unemployment need not be at all tantamount to an excessive real market wage. If the majority of workers are not satisfied with their earnings, and, if only they could afford it, they would not work, nor would they seek a job which pays the current wage rate because they value their labour more than that, this would mean that the high registered unemployment may in fact be considerably lower. One could conceive of a situation in which, despite the actually registered high unemployment, the current real wages are so low that if people could generate their income in a different way, then instead of unemployment, it would turn out that we would be facing labour oversupply! This sort of unemployment, where plenty of the unemployed declare their availability to and search actively for work, and as they are not sovereign in their decision on the labour supply volume, they simply cannot forego selling their labour and have to accept the current market price paid for it, could be referred to as forced and nonmarketable (paradoxically within the meaning of the neoclassical economic theory). This kind of reasoning leads to the conclusion that high unemployment need not arise from too high real wages, but from the fact that the labour market is specific to the extent that it cannot be analysed based on the rules governing markets with other goods, and therefore the neoclassical approach and its way of thinking about the labour market have to be abandoned. The imperfections of this market have the effect that the market mechanism itself does not work there and an external regulation is required. To illustrate this point, one might imagine a situation in which manufacturers of ordinary good, e.g. TV sets, are forced under penalty of death to manufacture and deliver a certain minimum level of supply to the market, 
irrespective of the market price of this good. With small demand and low price, it may turn out that they are selling below the costs, while there is excess of supply over demand on the market anyway! Does that mean that the real price of the product is too high and should be reduced? In the situation just described the market itself is not functioning properly since employers, taking advantage of their stronger position, may maintain low real wages over a long time, below the equilibrium that would have formed on the market if employees and the unemployed were sovereign in their decisions on the labour supply volume. Moreover, taking advantage of the high „forced unemployment”, employers can increase their labour force without raising wages because on a real and by definition imperfect labour market their wage rate is above the equilibrium point, which ensures that there is excess of supply over demand. On the real market, the wage curve is shifted downward to the right hand side, while the equilibrium price (,the market clearing wage”) is located lower than would have been the case for a labour market where all the employed and the unemployed could freely decide about their labour supply. The situation described may occur in a number of countries (e.g. in Poland) given that real wages grow slower than the costs of living, prices of consumption goods despite the continuous GDP growth. Adam Smith's laws, such as for instance „the market's invisible hand", do not work on this kind of the market, or at least, if they do, it is not to the extent assumed by today's neoclassical economics. Benefiting from their strong position, employers in addition refrain from raising wages accordingly even with increased labour productivity. In the situation when the labour market is monopolized on the employer's side, or when there is price collusion (formal or informal; as regards the price of work) between businesses, in particular between large corporations employing vast numbers of workers, thus exerting influence on how wages develop in a given industry, the unemployed available to work are greatly disadvantaged being forced to accept low wages imposed in advance. All this leads to a situation in which benefits obtained from one's labour may be unevenly distributed going mainly to a small group of company owners in the form of their high wages and the company's profits. This comes obviously as a loss to workers who are paid below the real value of their labour with the market mechanism itself unable to ever remedy this situation. If an external interference 
distributed the benefits arising from work fairly among all the employed, one could increase the real wages of most workers without increasing business costs and without staff reduction ${ }^{8}$.

To some extent, Karl Marx's analyses are coincident with the above theory. He claimed that in a capitalist system the reward for labour carried out by a considerable majority of workers would be at the level ensuring an exchange only for essential consumption goods. In other words, regardless of the country's economic development, workers' wages will stay low enough to ensure their subsistence at the level of a biological or social minimum. According to Marx, this wage amount is sufficient to sustain high labour supply. Of course, the real value of labour performed by those low-paid employees is substantially higher than their wages. The surplus thus created is taken over by the employer, although, as Marx believes, it belongs to the worker. Marx's theory emerged on the basis of Ricardo's observations and theory, a nineteenth century economist who formulated the ,iron law of wages". Ricardo, not unlike Marx, maintained that wages, whatever the situation in the free market economy, would be at a level ensuring minimum subsistence. In Ricardo's view, this is the level at which the labour market aims in equilibrium (Milkovich, Newman 1990: 38-39). Since the mid nineteenth century workers' wages increased considerably and one began to search for new theories. This is how the theory on marginal labour productivity and the already mentioned neoclassical model of competitive labour market came into being. For markets of certain variants of work, the premises of those theories hold true and they appear to be more useful than the critical judgment offered by Marx or Ricardo, for they are better at explaining and predicting how wages will develop in economy. However, as demonstrated before, the neoclassical approach to labour market does not seem to work in many other cases, in particular as regards the wages of young unskilled and discriminated workers, or those whose labour market position is weak for whatever other reasons. For a huge number of workers in today's economies, the theories of Marx and Ricardo may be more suited as they are more accurate in predicting the level of equilibrium and wages to develop on the labour market. This is due largely

\footnotetext{
${ }^{8}$ The theory of forced unemployment outlined here and the criticism of certain parts of the neoclassical labour market theory reflect the author's own considerations and views.
} 
to the fact that those people are the least sovereign in determining the amount of labour supply which they deliver to the market, with employers ruthlessly taking advantage of their weak position. For wages ensuring merely a bare subsistence minimum, in contemporary economies of developed countries there is still a vast amount of labour supply.

\section{Examining the effect of the level of unemployment on that of wages in enterprise sector in Poland in 2000-2014}

Defining the term ,wage and salary” is very important because of how it is used in this paper. Considering that the main source of data, namely the Statistical Central Office (GUS) publications, the term „wage and salary” should be understood as defined in the Statistical Yearbook of the Republic of Poland. This results from the fact that all information on wages and salaries used in this paper will refer precisely to this definition. Wages and salaries will thus encompass cash payments and benefits in kind or their equivalents payable to workers for work performed. The main component of wages and salaries, listed by GUS and the subject of the analysis outlined further on in the paper, is the so called „personal wage and salary”. A personal wage and salary encompasses, inter alia, the following items: basic wage, bonuses, awards and allowances (e.g. for length of service, for work of arduous nature), payment of overtime, remuneration for time not worked (e.g. paid holidays, sick leave), certain portion of benefits in kind and compensation (GUS 2006: 263). The GUS data used in this paper refer only to persons employed in an employment relationship.

In the empirical study, the unemployment phenomenon will be represented by the variable unemployment rate calculated and defined according to the way it is done in the national statistics (GUS). The data are presented in monthly terms. The rate of unemployment is the most commonly employed indicator and appears to be best reflecting the character of this phenomenon, which is why it was used in the paper. The high variability of the unemployment rate over the period examined is 
advantageous in terms of the objective of the paper, for it makes it easier to capture the potential effect of the phenomenon on the overall level of wages in Poland.

\subsection{Data used in the study}

The study pertaining to the entire country was conducted based on monthly data and covered the years 2000-2014, which allowed for eliciting a sufficient number of observations. The data used in the paper come from the publication of the Central Statistical Office and are available publicly (www.stat.gov.pl/gus). Owing to a large number of the source data used in this work, they could not be demonstrated here.

\subsection{Methodology of the empirical studies}

In the literature one can encounter a variety of methods for determining the effect of individual factors on the overall level of wages nation-wide. For solving the research problem Pearson linear correlation coefficient (R) was employed. This method was selected given that it enjoys a strong support of the economic theory. The majority of mechanisms to be observed of the wage development are linear in their nature. The advantage offered by this method is also the simplicity and universality of its application. In addition, the number of observations in the period at issue and the character of the phenomena analyzed allow for using the correlation coefficient, whereas some other methods could not have been used because of their restrictive limitations, rendering it impossible to draw meaningful conclusions from the studies. Pearson linear correlation coefficient naturally has, as any other method, its deficiencies. They were, however, kept to a minimum or were entirely eliminated thanks to the measures outlined below.

In the calculations, dynamics ratios were used calculated in relation to the analogous period (month) of the previous year (ratio indicating the change rate of the variable concerned). Likewise, the dynamics ratio of the change of wages was calculated in relation to the analogous period of the previous year (in both cases, the analogous period of the previous year $=100 \%$ ). This measure is aimed at eliminating potential seasonal fluctuations, as is the case, for instance, with respect to the wages paid every year in December (they are substantially higher than in other months). Applying the above mentioned ratio allows for confining the effect such 
seasonality has on the value of a correlation coefficient. In addition, it also reduces the trend effect. Next, the increments (the first differences) between the ratios from the subsequent periods were calculated. This enables one to eliminate the trend which, in spite of the measures outlined above, is clearly visible in certain situations if „raw” ratios are used. Having applied the first differences, the effect of the trend was minimized, which significantly reduced the risk of apparent correlation.

The next step was to discover the value of correlation coefficients between the variables with a lag and to test their significance. Thus, Pearson linear correlation coefficients with the „backed" variable (shifted to the left) demonstrated that the effect of the wage change on the variable change rate was appropriately lagged. Moreover, R coefficients with the variable shifted to the right (,accelerated") testified to the adequately lagged effect of the variable change rate on the change in the amount of wages. This allows for determining whether it is the variable having an impact on the overall level of wages, or whether it is perhaps that the change in the wage amount influences the specific variable. In order to make sure which variable was a response variable, a few shifts of time series were used (by 1, 2, 3, 6, 9 and 12 months, both to the left and right). The significance of the correlation coefficients calculated was tested using likelihoods of errors (p). In the paper, the threshold value for correlation significance was generally adopted at $\mathrm{p}=0,05$. In addition, coefficients of determination were calculated, which allowed for defining the extent within which the change in the level of wages could be explained by the change of the variable concerned.

\subsection{The study results}

For measuring the nation-wide correlations between the change dynamics of the rate of unemployment and that of average wages (nominal and real wages) in the enterprise sector, monthly data from $2000-2014^{9}$ were used. This means that the

9 1) The correlations referring to the overall level of wages for the whole country are calculated between the change dynamics of the values of individual variables in relation to the analogous period of the previous year. The „R" sign denotes the correlation coefficient, „R2" the coefficient of determination, while „p" the significance level, that is, the likelihood of accidental correlation error. The ,," sign denotes the shift to the right (acceleration) by a specific number (given in brackets) of time series periods of data describing the volatility of 
figures (in brackets) given in Tables 1 and 2 denote the shift, by a specific number of months, of time series of the data showing the change dynamics regarding the unemployment rate.

Table 1. Correlation between the unemployment rate and average nominal wages in the enterprise sector in $2000-2014$

\begin{tabular}{|c|c|}
\hline & NOMINAL WAGE (0) \\
\hline 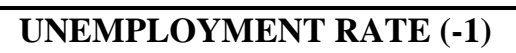 & $\mathrm{R}=-0.1047 ; p=0.164$ \\
\hline UNEMPLOYMENT RATE (-2) & $R=-0.0792 ; p=0.295$ \\
\hline UNEMPLOYMENT RATE (-3) & $R=-0.0746 ; p=0.325$ \\
\hline UNEMPLOYMENT RATE (-6) & $\mathrm{R}=-0.0146 ; \mathrm{p}=0.849$ \\
\hline $\begin{array}{l}\text { UNEMPLOYMENT RATE (-9) } \\
\end{array}$ & $\mathrm{R}=-0.0195 ; p=0.801$ \\
\hline UNEMPLOYMENT RATE (-12) & $\mathrm{R}=0.0304 ; \mathrm{p}=0.696$ \\
\hline UNEMPLOYMENT RATE (+1) & $\mathrm{R}=-0.1721 ; p=0.022 ; \mathrm{R} 2=0.03$ \\
\hline UNEMPLOYMENT RATE (+2) & $R=0.0438 ; p=0.563$ \\
\hline UNEMPLOYMENT RATE (+3) & $\mathrm{R}=-0.0659 ; \mathrm{p}=0.385$ \\
\hline UNEMPLOYMENT RATE (+6) & $\mathrm{R}=-0.0712 ; \mathrm{p}=0.352$ \\
\hline UNEMPLOYMENT RATE (+9) & $\mathrm{R}=-0.0312 ; \mathrm{p}=0.687$ \\
\hline UNEMPLOYMENT RATE (+12) & $\mathrm{R}=0.0311 ; \mathrm{p}=0.690$ \\
\hline $\begin{array}{l}\text { UNEMPLOYMENT RATE (0) } \\
\end{array}$ & $R=-0.0080 ; p=0.916$ \\
\hline
\end{tabular}

Source: Self-reported data based on GUS data.

The results included in Tables 1 and 2 show that there is a clear, although weak, linear correlation between variables. The change in the rate of unemployment impacted negatively the change dynamics of average wages paid in the enterprise sector during the period studied. This effect was lagged by one month and stronger

a specific wage determinant in relation to the time series of the data describing the volatility of average wages themselves. In other words, the , + " sign indicates the lagged (by the number of periods given in brackets) influence of a specific variable on the change dynamics of wages. Analogously, the ,-" sign denotes a shift to the left (lag) of time series of data describing the volatility of a specific determinant, meaning that it indicates the lagged (by the number given in brackets) influence of the change dynamics of wages on the change of a specific variable. 
for real wages (also the likelihood of error was considerably lower for real wages). The coefficient of determination was at 0.04 ; thus, only $4 \%$ of the change dynamics of average real wages was explained by the rate of change of the unemployment rate. It was not possible to find any significant linear correlation which would suggest that the change in average wages would have an effect on the rate of unemployment in Poland over the years analysed.

Table 2. Correlation between the unemployment rate and average real wages in the enterprise sector in 2000-2014

\begin{tabular}{|c|c|}
\hline & $\begin{array}{c}\text { REAL WAGE } \\
\text { (0) }\end{array}$ \\
\hline UNEMPLOYMENT RATE (0) & $R=-0,0347 ; p=0.646$ \\
\hline UNEMPLOYMENT RATE (-1) & $\mathrm{R}=-0.0832 ; \mathrm{p}=0.271$ \\
\hline UNEMPLOYMENT RATE (-2) & $\mathrm{R}=-0.0515 ; \mathrm{p}=0.497$ \\
\hline UNEMPLOYMENT RATE (-3) & $\mathrm{R}=-0.0468 ; \mathrm{p}=0.538$ \\
\hline UNEMPLOYMENT RATE (-6) & $\mathrm{R}=-0.0145 ; \mathrm{p}=0.850$ \\
\hline UNEMPLOYMENT RATE (-9) & $\mathrm{R}=-0.0584 ; \mathrm{p}=0.451$ \\
\hline UNEMPLOYMENT RATE (-12) & $\mathrm{R}=0.0624 ; \mathrm{p}=0.424$ \\
\hline UNEMPLOYMENT RATE (+1) & $R=-0.2002 ; p=0.007 ; R 2=0.04$ \\
\hline UNEMPLOYMENT RATE (+2) & $\mathrm{R}=0.0504 ; \mathrm{p}=0.505$ \\
\hline UNEMPLOYMENT RATE (+3) & $\mathrm{R}=-0.0751 ; \mathrm{p}=0.322$ \\
\hline UNEMPLOYMENT RATE (+6) & $\mathrm{R}=-0.0404 ; \mathrm{p}=0.597$ \\
\hline UNEMPLOYMENT RATE (+9) & $\mathrm{R}=0.0070 \mathrm{p}=0.928$ \\
\hline UNEMPLOYMENT RATE (+12) & $\mathrm{R}=0.0437 ; \mathrm{p}=0.575$ \\
\hline
\end{tabular}

Source: Self-reported data based on GUS data.

One should further mention that a strong negative correlation between the change dynamics of wages (nominal and real) and that of unemployment was elicited when no differencing and no shifts were applied $(R=-0.6493, p=0.000-$ for real wages). These findings demonstrate a strong trend effect, which may lead to 
false conclusions brought about by apparent correlation. Following the application of the first differences, the trend effect was minimized, which can be gleaned from Tables 1 and 2, where there is no linear correlation between the variables with no shifts, and after differencing. This measure improves the reliability of the study results, especially given that they are supported by the economic theory..

\section{Conclusion}

The analysis of correlation coefficients conducted in this paper demonstrated clearly that the rate of unemployment was a determinant of the overall level of wages in the enterprise sector over the period examined. The nation-wide study showed a negative effect of the rate of unemployment on the change dynamics and level of average (nominal and real) wages in the enterprise sector. This effect was lagged by one month suggesting that the higher the rate of unemployment in the country, the lower average wages in the sector were to be expected. The analysis results are consistent with the theory and findings produced by other empirical studies presented in the paper.

Based on the results from the survey on Hungarian family business profile at the turn of 2017/18 one can conclude that large majority (around 91\%) of these firms are small-sized and medium-sized (only less than 8\%) and large-sized (bit more than $1 \%$ ) to a less fewer extent.

Microenterprises can certainly develop into small businesses - involvement of more family members from the next generation by the founder and his/her spouse into the operative work means the key for this process. This is clearly the best outcome both from the perspective of the family and the company.

They are less able however for the next shift: hiring external, non-family professionals into the top management. It would be especially crucial for small businesses in the process of becoming a medium-sized business.

The developmental pattern of their governance practices refers to their increasing level of professionalization: the governance mechanisms of the business 
and ownership become more separated from each other and also from the family. The relationship between the firm and the family turns into a more regulated form.

On the other hand, the fact that HR-related topics are relatively less significant reflects back the fractual nature of their professionalization. Their Family Councils may fulfill the persistent function of bridging family and company, but are less able to satisfy their other important, long-term function regarding the planning of the maintenance of family control over the company.

My study is subject to more limitations. Firstly, as a general note, the original research was exploratory in nature, the results only deliver a bird's view of the field. The more focused the analysis was, the more grained the picture I got from the data became. The results are representative for the whole population only at the case of the first questionnaire. With the second questionnaire, I was rather able to explore tendencies based on which I am able to conduct more targeted research in the future. Secondly, the analysis is based on the scholarship of the field, which is not countryspecific - detailed analysis of the local, Hungarian institutional factors and legal context was not included (with the exception of the entrepreneurial family history). The empirical results can be assessed and compared with other research results, but one should always keep in mind this important limitation of the research.

\section{References}

Blanchflower D.G. (2001), Unemployment, well-being, and wage curves in Eastern and Central Europe, ,Journal of the Japanese and International Economies”, vol. 15 no. 4, pp. 364-402.

Blanchflower D.G., Oswald A.J. (1994), The wage curve, The MIT Press, Cambridge MA, London.

Buettner T. (1999), The effect of unemployment, aggregate wages, and spatial contiguity on local wages. An investigation with German district level data, „Papers in Regional Science”, vol. 78 no. 1, pp. 47-67.

GUS (Central Statistical Office) (2006), Rocznik statystyczny Rzeczypospolitej Polskiej 2006, GUS, Warszawa.

Holmlund B. (1991), Unemployment persistence and insider-outsider forces in wage determination, OECD Economics Department Working Papers no. 92, OECD Publishing, Paris, https://www.oecdilibrary.org/docserver/883783738373.pdf?expires=1552978315\&id=id\&accname=guest\&checksum =5 9924C96F4F3CBD9A62A318D0A178614 [18.03.2019].

Kamerschen D.R., McKenzie R.B., Nardinelli C. (1991), Ekonomia, Fundacja Gospodarcza NSZZ „Solidarność", Gdańsk. 


\section{THE EFFECT OF UNEMPLOYMENT ON THE LEVEL OF WAGES IN THE ENTERPRISE}

Kwiatkowski E. (2007), Bezrobocie. Podstawy teoretyczne, Wydawnictwo Naukowe PWN, Warszawa. Milkovich G.T., Newman J.M. (1990), Compensation, 3rd ed., Richard D. Irwin, Inc., Boston.

Oleksyn T. (1997), Praca i płaca w zarządzaniu, Międzynarodowa Szkoła Menedżerów, Warszawa. Sen A. (1975), Employment, technology and development, Oxford University Press, Oxford-London. Sinclair P.J. (1987), Unemployment. Economic theory and evidence, Blackwell, Oxford.

Solow R.M., Taylor J.B., Friedman B.L. (eds.) (2002), Inflacja, bezrobocie a polityka monetarna, Wydawnictwo CeDeWu, Warszawa.

\section{Websites}

www.stat.gov.pl/gus [01.06.2015]. 